\title{
Review on Motivational Theories \& Models: Its application for Employees' Retention in Organizations
}

Syed Sadullah Hussainy

Lecturer

Faculty of Business

Arab Open University

Phone: +968-96491723

Email: syed@aou.edu.om

Sultanate of Oman

\section{ABSTRACT}

Employees are the most important resource of an organization. Their significance to organizations calls for not only the need to select the best employees but also the necessity to retain them in the organization for a long period. This paper focuses on the review and analysis of motivational theories and models to identify how their ideas can be used for the retention of employees in the organization. This research closely looked at the following five theories and three models: 1. Job embeddedness theory, 2. Maslow's theory of Hierarchy of Needs, 3. Hertzberg's theory, 4. David McClelland's theory of motivation and 5. Job coupling theory etc., The models were chosen are 1) Zinger Model, 2) ERC's Retention Model. 3) Integrated System for Retaining Employees. The study concluded that further investigations need to be conducted on employees' retention on different businesses and industrial setup to better comprehend this complex field to better equip organizations with the knowledge necessary to improve their retention capability.

\section{Keywords: Motivational theories and model, employees' retention}

\section{Introduction}

The subject of employee retention has gained popularity among experts, researchers, and practitioners due to its growing significance for the business organization. Retention of employees has become a common challenge for all organizations across the industry. Hyper-competitive business environment, the job-hopping mindset of the current generation and attractive job opportunities for the best talents, etc. are some of the important factors affecting the retention of employees in organizations (Kossivi.B, Xu.M, Kalgora.B, 2016). Human resources is an important resource of the organization to gain sustainable achieve competitive advantage and the role of a business function devoted to the management of Human Capital has never been taken as a desirable and enjoyable activity (Pahuja, Dr. Saloni \& Dalal, Ramesh Chander, 2012). Companies design pleasing slogans to show the significance that they have for their employees, such as "It is our people who make the difference where it matters most..." (Tesco 2002) and “...we believe that competitive advantage is achieved through our people..." (Kellogg 2002) and "Your contribution has been valuable to us and has determined our success". And "We strongly believe you have the potential to take this organization to the height of success and glory" etc.

The boss who is desperately trying to retain deserving employees only says such words. But it is an unpleasant truth, such a level of appreciation and acknowledgment is extended mostly if the employee has already made a plan to leave the organization. Unluckily, we live in an imperfect world and doing the right thing at the right time does not seem so logical to most people. It is essential that organizations need to be proactive in designing retention- focused practices by measuring and evaluating their psychological contract and commitment from time to time (Trevor, C.O., Gerhart, B. and Boudreau, J.W. 1997). Employees who stay with the company for a longer time contribute efficiently and become an integral part of the company and the position. The organization will be suffering a loss when the employees leave their job once they are trained and this means a double problem for the first company. First, the organizations will be directly affected by the employee not being available with the company and secondly, the employee is now contributing to its competitors and the person who replaces the outgoing employee may not be able to come at par that early. So better is to retain the employee and make sure he/she remains motivated and have a positive attitude toward his/her job and the organization. If such things are in practice from the beginning, the employee would not leave the organization. 


\section{II. the objective of the Study}

The objective of this study is to analyze and explain how the ideas of motivational theories and models can be applied and used for employees' retention in the current organizational environment.

\section{Methodology}

This paper follows the descriptive research method and it is predominantly based on extensive literature review and secondary data. Review has been done to identify the blend of motivational theories and model and the secondary data from previous researches were used and to get the answers, historical facts, data and past work of literatures were reviewed to explain how applying the ideas of these motivational theories and model in the present organizational setup can be useful for employees' retention. This article offers an explanation that justifies that motivational theories and models can be handy in developing suitable retention practices and enhancing retention in modern organizations. This study illustrates the explanation of how effective employee retention practices can be developed through motivation theories and models and how they serve as a strategy to enhance employees' retention.

\section{Synthesis of Motivational Theories and Models}

Experts have developed several theories and models for supporting organizations in improving motivation and retention and also reducing the problems associated with excessive employees' turnover. These theories and models give a wealth of ideas and insights on the best practices to be implemented and practiced in an organization for motivating employees to stay with the organization. With this background, the author attempted to provide a synthesis of employee motivational theories and models by carefully reviewing and analyzing them. The author identified the most relevant traditional theories and explained which are useful for employees' retention. The following theories and models were selected 1.Job embeddedness theory 2.Maslow's theory of Hierarchy of Needs, 3.Hertzberg theory 4.David McClelland's theory of motivation and 5. Job coupling theory and the following models are selected 1.Zinger Model, 2. ERC's Retention Model. 3. Integrated System for Retaining Employees given their emphasis and reported significance on employee retention.

\section{Job embeddedness theory}

Job embeddedness theory proposes various means of identifying challenges that could lead to undesirable turnover in the organization. It was developed by Brooks C. Holtom and his colleagues at Georgetown University through their research ("Increasing human and social capital by applying job embeddedness theory," published in Organizational Dynamics in 2006) consist of various elements leading to employee retention or turnover. It incorporates a range of ideas that may be useful for organizations. This theory is based on three elements that show the level of association that employees may develop within their organization. These can be broadly categorized as Fit, Link, and sacrifices. Fit: It indicates employees' compatibility with the job and the organization. It includes having the necessary job knowledge, personal skills, a favorable working environment and a connection with the community. When employees have perfect fit will display motivation, interest, commitment, and loyalty with the organization and certainly, they are more likely to stay with the organization. Links: Link indicates how an employee is connected to the people and the organization and community. These connections may between management and employees or connection between colleagues and friendship or relationship with them. Good links between an employee and their organization can result in improved job embeddedness. Sacrifice: It shows the level of disturbance an individual would experience if they leave their job. If the employee feels that they will be sacrificing good relationships that they have nurtured with their colleagues, or if they are losing good projects or programs, in short, the cost of leaving is the organization is higher than its benefit then they might stay with the organization. By these three elements, the organization can assess to what extent employees may be at risk of leaving the organization. This theory also offers an application to promote and improve employee retention and reduce the cost and risk of excessive turnover (Brooks C.Holtom, Terence R. Michell \& Thomas W. Lee, 2006).

\section{Maslow's hierarchy of needs}

In 1943, psychologist Abraham Maslow wrote "A Theory of Human Motivation". This theory aimed to describe what people needed to feel motivated. Maslow's hierarchy is also very crucial in the retention of employees. According to Maslow, there are five levels of needs people must have met to feel motivated. These five needs are grouped under two categories such 


\author{
E-ISSN: 2469-6501 \\ VOL: 6, ISSUE: 1 \\ January/2020 \\ DOl:10.33642/fjbass.v6n1p5 \\ https://ijbassnet.com/
}

as basic needs (physiological, safety and social) and the upper-level needs (esteem and self- actualization). Organizations should strive to meet all the needs of employees. A young employee who has just completed their studies may focus on satisfying basic needs such as food, clothing, shelter, safety, family, and friends in the first few years of his employment and will see taking jobs or employment is the means to satisfy them. After gaining work experience of a few years will develop the need for creating identity in the workplace or society. To satisfy these needs, he will look for a better job and a responsible position in the work. It is important that organization to satisfy the basic needs of their efficient employees but also awarding them responsible position at work to satisfy their esteem needs. This will encourage the employees to become committed and stay with the organization for a longer period. Such practices develop a positive feeling about the organization and employees understand that their organization is concern about their needs and they will reciprocate by showing their loyalty and commitment to the organization. Contrary to this, if an employee subject to a bad and very toxic environment will not be committed and interested in staying in his job (Hanif, Ayesha \& Khalid, Wajiha \& Khan. T.N., 2013).

\title{
Herzberg's theory (Motivator-hygiene)
}

In the 1950s, Frederick Herzberg researched on employee retention and motivation and finally develops duel dimensional job satisfaction theory. Herzberg assumed that job satisfaction consists of two dimensions such as dis-satisfiers he called it hygiene factors and satisfiers, also called motivators. He assumed that employees can be retained by reducing dissatisfaction and maximizing satisfaction. He believed that the motivator leads to employee satisfaction whereas the hygiene elements cause dissatisfaction. Dis-satisfier or hygiene factors include a relationship with the management, company policy, and relationship with colleagues, working conditions, supervision, relationships, and salary. Satisfiers include job promotion, achievement, growth and advancement, responsibility and recognition. Organizations may use Herberg's motivation and hygiene factors to improve their retention. Taking feedback and suggestions can help determine approval with the hygiene aspects and proactive steps need to be taken if feed result found dissatisfactory (Almaaitah, Mohammad \& Harada, Yoshifumi \& F Sakdan, M \& Perlis, Ayman, Mahmoud \&, Almaaitah, 2017)

\section{McClelland's Human Motivation Theory}

David McClelland's 1961 wrote a book called "The Achieving Society". He identified three motivators of human such as the need for achievement, power, and affiliation. He believed that all the human being holds these traits of motivation but only one will be dominant. The organization should try to identify the dominant trait of the motivation of their employees. By identifying this organization can set a goal, give feedback and set the best way of motivating and rewarding their employees (Reuben M. Badubi, 2017). Achievement Dominance: Employees with achievement dominance need more likely to be happy and satisfied when they can achieve challenging goals and targets. For such people, the organization should engage in some challenging projects. Such people create a solution and can work on their own with less assistance. Affiliation Dominance: Employees with affiliation need to give importance to developing a relationship with others and want to be liked by others in the organization. They also prefer to collaborate rather than competing with others. The Organization should make them the team member and assign them with low-risk work for retaining them. Power Dominance: The people want to have power and enjoyed being powerful and influencing others in the organization. They give preference to recognition and status in the organization. Keeping them engaged may require continuous challenges that include advancing their career aspirations.

\section{Job Coupling}

A publication by the African Journal of Business Management outlines Job Coupling as a retention strategy. The Job coupling model consists of two dimensions: "on-job-coupling" and "off-job-coupling." They identified three elements such as linkage, fitness, and sacrifice as key factors in the employees' retention.

Linkage: It is the connection employees have with their organization and the members of the organization. How much deep connection the employee is having with the organization and the people of the organization determine his tenure with the organization. The theory suggests the more linkages an employee holds, the more they are "bound" to the organization. Fitness: It is the perception of employees about their self-compatibility with the organization. Do their skills align well with the needs and demands of their position within the organization? Do they have a very good rapport and affiliation with colleagues 
and other members of the organization? This theory suggests employees who find fitness within the organization will show higher job satisfaction and reduced intention to leave. Sacrifice: It refers to the price the employee would pay, financially, socially, career-wise and psychologically, if they left the organization. The theory suggests the more sacrifices they would have to make; the less likely they may be to leave. The linkage aspect suggests that organizations should promote cordial relationships among employees to make them connect very closely. Besides that fitness aspect is more closely related to worklife balance. Employees should be given challenging responsibilities and the same time organizations should ensure that they are not frustrated. Sacrifice may suggest that overall organizational life should be very attractive in such a way that it will put employees in a position where they cannot financially or psychologically afford to leave (Zheng WeiBo, Sharan Kaur and Tao Zhi, 2010).

\section{Motivation model}

There are three models of employee motivation and retention has been chosen. They are 1) Zinger Model, 2) ERC's Retention Model. 3) Integrated System for Retaining Employees. A brief explanation of these models follows:

\section{Zinger Model}

David Zinger is a Canadian management consultant whose work is designed to fostering relationships to increase employee engagement in the organization. Based on his research, he has introduced a model throws lights on various aspect of employee engagement, dedication, and involvement.

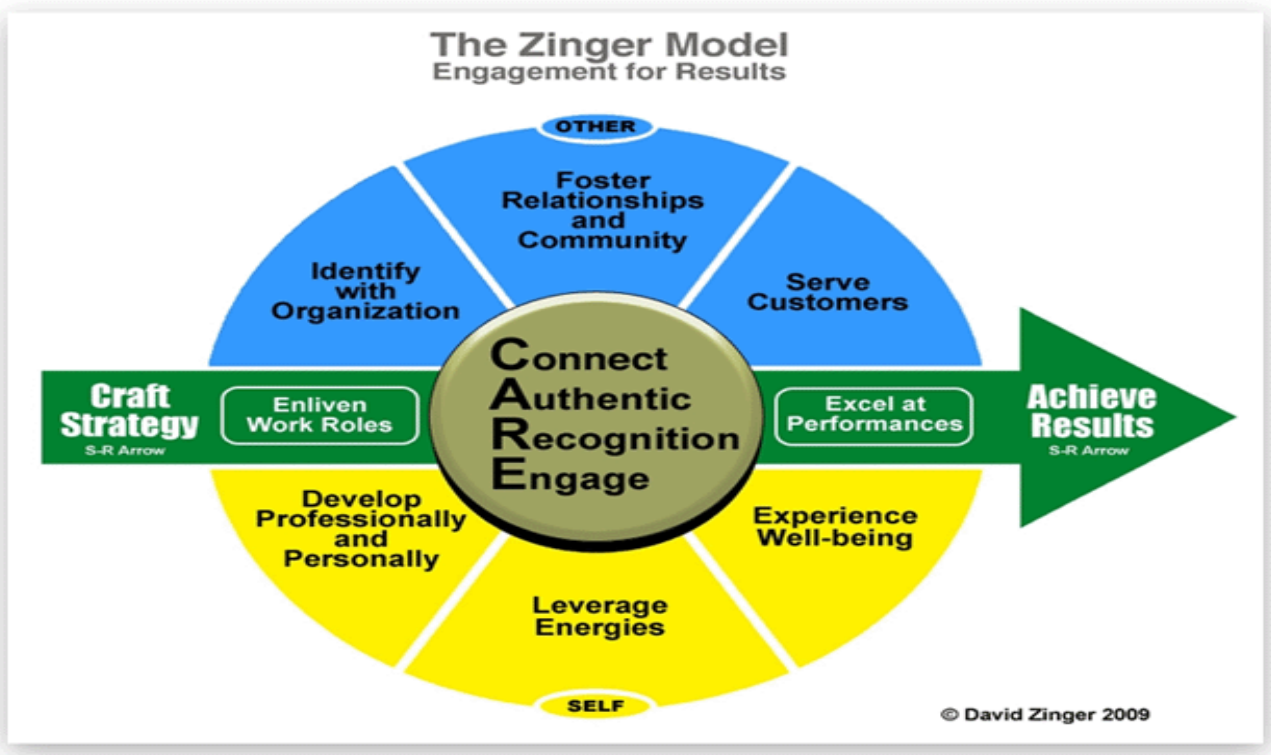

Sultana Nazia \& Bushra Begum,(2014); Employees retention practices in Indian Corporate- A study of select MNCs; International journal of Engineering \& Management Science, Vol 4 (3) pp 361-368.

Employee retention is an activity of keeping employees with the organization. It aims at reducing turnover by nurturing a positive working environment to promote engagement, giving appreciation to employees, and providing competitive pay and benefits and healthy work-life balance. This model gives twelve different drivers for enhancing employee engagement levels. They are (1) Organization should achieve results through proper plan and execution (2) Craft strategies to engage employees considering the organization and employees requirement (3) Enliven: Employees mostly like interesting and challenging jobs organization should work on removing the boredom factor from the work (4) Motivating employees to work hard by rewarding for the hard work which creates a self-esteem among employee (5) Managers should always be connected with their subordinates and communication with them openly, listen to their problems and ask for suggestions. (6) Be real, genuine and authentic, this is what is expected from the leader he has to be authentic when addressing the problem of employees and does justice. (7) Live recognition: Give recognition to employees in front of everyone not just to boost their morale but also encourage them to stay with the organization for a long time. (8) The desired results can be achieved in the fastest possible 
way only if employees are fully engaged. (9) Identify with Organization: Employees stay in the organization for long years if they feel connected to their organization. (10) Serving customers by creating a culture and tradition. Only engaged employees will be able to serve the customer in a better way (11) Develop personally by up-gradation of skill according to the requirement and (12) Attain happiness with satisfied and happy employees. David Zinger Model on Employee Engagement considers all important aspects that could impact the involvement, engagement, and dedication of employees.

\section{ERC's Retention Model}

The Employee Retention Connection (ERC) model focuses on transforms organizational culture and enhances competitive edge. Retention Connection builds a tailored reward and recognition system to fit the organization's culture, Identifying activities, attitudes, and contributions to be recognized and rewarded which help to properly friendly culture in the organization. Employee Retention Connection's decades of applied organizational experience indicate three primary drivers of employee retention.

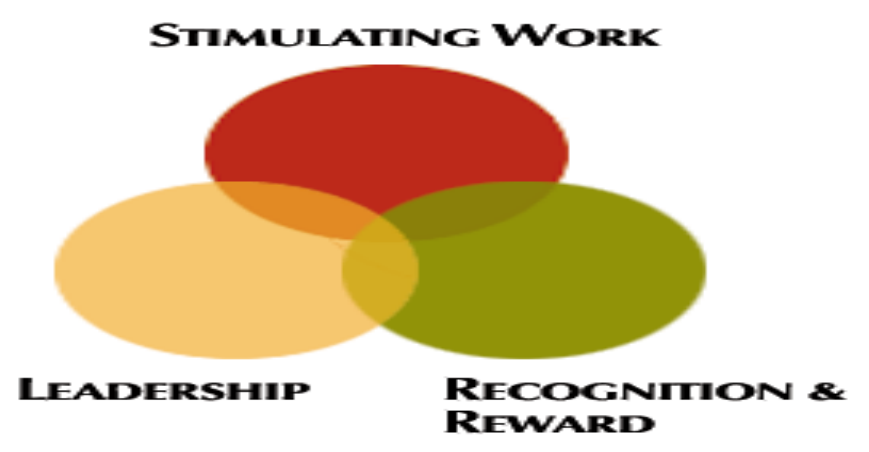

Sultana Nazia \& Bushra Begum,(2014); Employees retention practices in Indian Corporate- A study of select MNCs; International journal of Engineering \& Management Science, Vol 4 (3) pp 361-368.

Work can be made stimulating by giving a variety of assignments, autonomy to make decisions, resources and support provided to do good work, an opportunity to learn, feedback on the result and understanding the significance of one's contributions. Motivational Leadership also helps retain employees therefore leaders should champion change and must be open to new ideas. They should inspire a shared vision of organization direction, develop the capabilities of others and become a model for behaviors that reflects organization values. Companies should recognize and reward a job that is done well and should reinforce desired behaviors and create emphasis and focus on recognition. They should celebrate successes to build self-esteem and enhance solidarity and teamwork. Integrated System for Retaining Employees

Integrated System for Retaining Employees

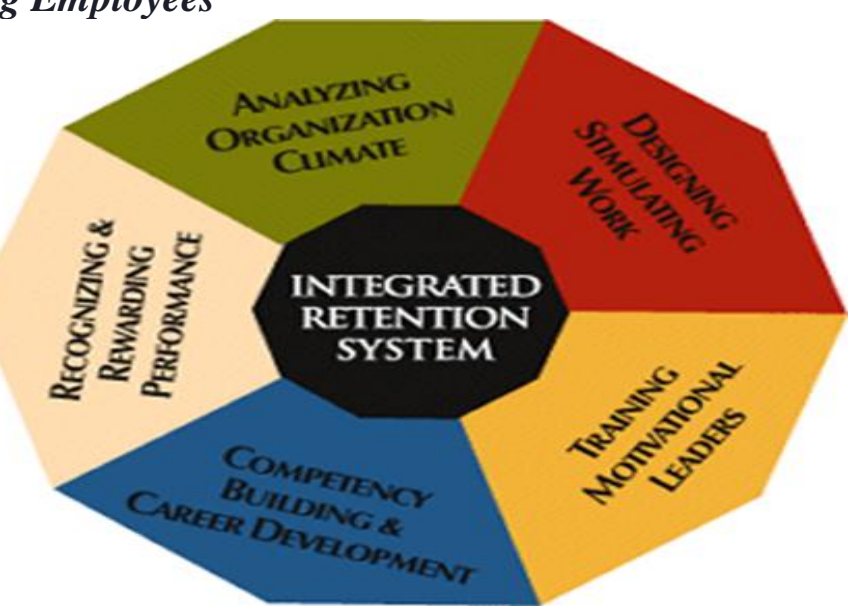

Sultana Nazia \& Bushra Begum,(2014); Employees retention practices in Indian Corporate- A study of select MNCs; International journal of Engineering \& Management Science, Vol 4 (3) pp 361-368. 


\author{
E-ISSN: 2469-6501 \\ VOL: 6, ISSUE: 1 \\ January/2020 \\ DOl:10.33642/fjbass.v6n1p5 \\ https://ijbassnet.com/
}

The Employee Retention Connection transforms the organization culture and enhances the competitive edge through the following five-phased approach: ERC begins by analyzing the organization's motivation and retention culture through surveys and focus groups that are the motivating and demotivating aspects of the culture. ERC concentrates on designing highinvolvement job and work assignments and trains supervisors and managers in proven methods of motivational leadership. ERC delivers a plan for employee career paths and skill-building and builds a tailored reward and recognition system to fit your organization's culture.

\title{
VI. Finding \& Discussion
}

The literature review and analysis of motivational theories and models give us the idea that the motivational theories and models can be very useful in retaining efficient employees and gaining their loyalty and commitment towards the organization. Job coupling theory and job embeddedness theory give an idea that the organization should appropriately do recruitment and selection and ensure that the right person should be assigned for the right job to achieving the compatibility and fit between job and employee. The organization working culture should be based on trust and positive relationships among the organizational members and the same can be gained through cultivating an open communication climate. The culture of cooperation rather than the competition should be created and employees should have easy access to their superiors and managers to discuss their grievances. The job should be challenging and interesting and the culture of appreciation and teamwork which will make the employees stay with the organization. In such situations, the employee will have the feeling that the cost of leaving the job will be more than its benefits.

Employees look at the organization as a means of achieving professional and personal goals. In this regards respect, recognition and reward are considered as the fundamentals of employees' retention. Job and employment will satisfy the basic order needs of employees but these three factors will help an employee to create its identity and satisfy his upper-level needs. Respect is regard, special appreciation, or consideration given to people. As the pyramid shows, respect is the foundation of retaining employees. Recognition and rewards will have little result if an organization doesn't respect employees. Recognition can be described as "special attention". It is special attention the organization should give to the good performers and failing to do may lead to dissatisfaction and low morale and turnover. Rewards are the extra perks the company offers beyond the basics of respect and recognition that make employees work hard and put all their best effort. Rewards are important for motivation and retention of employees (Cherian, Jacob, \& Jacob, Jolly 2013).

Good compensation and benefits, recognition, reward, and promotion, etc., are not enough for retaining employees but employees want good relationship with C-suites and top management, open-door policy, good working culture, team-work, good companies' policies, strategies, rules, and regulations, etc., also affect employees' intention to stay with organization. Hertzberg believed that the motivators lead to employee satisfaction whereas the hygiene elements cause dissatisfaction. Taking feedback and suggestions can help to determine the employees' approval with the hygiene aspects and proactive steps need to be taken if feed result found dissatisfactory (Almaaitah, Mohammad \& Harada, Yoshifumi \& F Sakdan, M \& Perlis, Ayman, Mahmoud \&, Almaaitah, 2017).

David McClelland's explained different traits of motivation but the only one will be dominant and the Organization should identify the dominant trait of employees. (Reuben M. Badubi, 2017). People are different concerning their nature, characteristics, and behavior. Some like challenging jobs and some gives priority to better working culture and relationship among organizational member and some will be happy having with higher responsibility and authority. Organizations should try to provide interesting and challenging jobs that will continuously enhance employees' skills and give a feeling of achievement. Likewise developing a better relationship amongst organizational members creates co-ordination synergy and positive psychological contract amongst employees. Besides that proper delegation of authority and responsibility is also another important aspect of retaining employees in the organization.

Zinger model gives different drivers for retention such as formulating proper planning and strategies, interesting and challenging jobs, respect, open communication climate, reward and recognition, open communication climate, open-door policy, excellent leadership, and proper training and development, etc., are factors which contribute in achieving high employees retention in the organization. Whereas the ECR model emphasis stimulating work which can be gained by varieties 
of assignments, autonomy to make decisions, resources and support, opportunity to learn, feedback on the result of one's contributions is the factors that help in high employees' retention. It also stresses on leadership, vision, and values of the organization beside reward, recognition, and teamwork.

\section{Conclusion}

The organization should retain its efficient employees which is crucial for remaining and surviving in the present competitive business environment. Although this study attempted to explain how the motivational theories and models can be useful for employees' retention in the organization. Employees' retention is a complex area of human resource needs further investigations in different organizational and industrial setup to better equip organizations with the knowledge necessary to improve their retention capability are needed.

\section{References}

Almaaitah, Mohammad \& Harada, Yoshifumi \& F Sakdan, M \& Perlis, Ayman, Mahmoud \& Almaaitah. (2017). Integrating Herzberg and Social Exchange Theories to Underpinned Human Resource Practices, Leadership Style and Employee Retention in Health Sector. 3.

Brook C. Holtom, Terence R. Mitchell Thomas W.Lee, (2006); Increasing human and social capital by applying job embeddedness theory; Organizational Dynamics, Vol. 35, No. 4, pp. 316-331, 2006 ISSN 0090-2616/\$ - see frontmatter 2006 Elsevier Inc. All rights reserved. doi:10.1016/j.orgdyn.2006.08.007, Available at www.organizational-dynamics.com.

Brooks C.Holtom, Terence R. Michell \& Thomas W. Lee (2006); Increasing human and social capital by applying job embeddedness theory: Organizational Dynamics, Vol. 35, No. 4, pp. 316-331, 2006 ISSN 0090-2616/\$ doi:10.1016/j.orgdyn.2006.08.007, Available online at: www.sciencedirect.com

Cherian, Jacob, \& Jacob, Jolly. (2013). Impact of Self Efficacy on Motivation and Performance of Employees. International Journal of Business and Management, Vol. 8(14):80-88.

Hanif, Ayesha \& Khalid, Wajiha \& Tahir Nawaz Khan, Dr. (2013). Relating Maslow's Hierarchy of Needs with Employee Turnover and Retention: Case Study of Local Telco. International Journal of Human Resource Studies. 3.51. 10.5296/ijhrs.v3i2.3864.

Kossivi, Bodjrenou \& Xu, Ming \& Kalgora, Bomboma. (2016). Study on Determining Factors of Employee Retention. Open Journal of Social Sciences. 04. 261-268. 10.4236/jss.2016.45029.

Pahuja, Dr. Saloni \& Dalal, Ramesh Chander. (2012). Achieving Competitive Advantage through HR Practices: A Case study. Journal of Human Resource Management. 1. 35-43.

Reuben M. Badubi, (2017); Theories of Motivation and Their Application in Organizations: A Risk Analysis: International Journal of Innovation and Economic Development, Volume 3, Issue 3, August 2017, Pages 44-51, DOI: 10.18775/ijied.1849-7551-7020.2015.33.2004, URL: http://dx.doi.org/10.18775/ijied.1849-7551-7020.2015.33.2004.

Sultana Nazia \& Bushra Begum,(2014); Employees retention practices in Indian Corporate- A study of select MNCs; International journal of Engineering \& Management Science, Vol 4 (3) pp 361-368.

Trevor, C.O., Gerhart, B. and Boudreau, J.W. (1997) Voluntary Turnover and Job Performance: Curvilinear and the Moderating Influences of Salary Growth and Promotions. Journal of Applied. Psychology, 82, 44-61.

Zheng WeiBo, Sharan Kaur and Tao Zhi (2010); A critical review of employee turnover model (1938-2009) and development in perspective of performance: African Journal of Business Management, Article Number - A4AE50218071, Vol.4(19), pp. 4146-4158. 